\title{
Introduction: Islam, Space, and the Internet
}

\author{
Giulia Evolvi \\ Lecturer, Erasmus School of History, Culture, and Communication, \\ Erasmus University Rotterdam, Rotterdam, Netherlands \\ evolvi@eshcc.eur.nl \\ Maria Chiara Giorda \\ Associate Professor, Department of Humanities,Università Roma Tre, \\ Rome, Italy \\ mariachiara.giorda@uniroma3.it
}

This special issue comes from a panel we organized at the conference of the European Association for the Study of Religion (EASR) held in Bern in June 2018. ${ }^{1}$ The panel, titled "Space, Religion, and the Internet," aimed at exploring the relationship between religion and new media by considering the spatial turn in Religious Studies. We launched an open call for the panel and, while it was not restricted to a specific religion, it mostly attracted papers on Islam. This resulted in a panel exploring digital Islam in countries that are not predominantly Muslim, analyzing topics that included Salafi and fundamentalist practices, gender performances within Islam, online Islamophobia, and the use of the Internet to counteract stereotypes. Following the panel, we decided to publish this special issue with a focus in Islam in Europe and North America.

The growing academic interest on Islam and the Internet, shown by the significant number of submissions on the topic we had for the EASR conference panel, has different causes. First, Muslims living in non-Muslim countries often employ digital media to gain knowledge about Islam, negotiate religious practices, explore ways to be part of a community, consume Muslim-inspired pop culture, and find like-minded people to discuss religious and cultural backgrounds (Echchaibi, 2011; Bahfen, 2018). Second, the growth of digital practices also sheds light on the intersection between offline and online Islamophobia, which is a pressing social issue. Together with street-level Islamophobia, the Internet may offer venues for stereotypes, abuses, discriminations and threats

1 For information, see http://www.easr2o18.org/. 
against Muslims (Awan, 2014; Evolvi, 2017a, Vitullo, 2019; Elfenbein, Bakaari \& Schafer, 2021). Third, Muslims who live in the European and North American context are often a stigmatized minority and their everyday experiences are overlooked by so-called mainstream media. Thus, the Internet may become a tool to counteract stereotypes and hate, connect with society at large, and normalize the practice of "lived Islam" in everyday settings (Frisina, 2011; Van Zoonen, Vis \& Miheli, 2011; Evolvi, 2017b). In an intersectional perspective, this is particularly relevant for Muslim women, who may be further discriminated against for their gender, and who may use digital platforms to negotiate their agency and visibility, especially when they wear a veil or a form of head cover (Echchaibi, 2013; Wheeler, 2014; Peterson, 2016, 2020, Borrillo, 2017).

The previous academic literature on Islam and the Internet shows how digital media can offer venues to negotiate practices and identities. However, what we aim to explore in this special issue is the Internet's potential to create digital spaces for narratives written by Muslims and about Islam.

With attention to the increasing focus on space and materiality in Religious Studies (Burchardt \& Höhne, 2015; Hutchings \& McKenzie, 2016) and inspired by the interest in Islam and the Internet showed at the EASR conference, we collected articles with the following questions in mind: How do digital technologies affect religious identities within Muslim communities? How can the Internet help Muslims to define and live religious spaces physically? How can we conceptualize the Internet as a sacred/religious space for Muslims? What kind of narratives about Islam and written by Muslims are situated on the Internet?

This introduction will, first, describe the spatial turn in Religious Studies that contributed to motivating our interests for the subject. Then, we will proceed by talking about theories and approaches that conceptualize the Internet in spatial terms. We will also discuss the notion of materiality as connected to Internet spaces. In doing so, we will offer an overview of the articles in this special issue, showing how they address the notion of space and materiality in relation to Muslim digital media practices.

\section{Religion and Space, Space and Religions}

A first topic, transversal to all the articles in this special issue, is that of space. In particular, the articles draw from the Religious Studies approach to space, which we will discuss in this section. During the last centuries, scholars progressively developed different theoretical approaches, moving from the study of Christian space to the study of space to Christianize (since the aim of mapping the territory was to know it and conquer it), up to the study of a "religious space" through a Geography of Religions. 
The first steps toward a Geography of Religions were made in the 16th century with the emergence of so-called "Sacred Geography," which aimed to map the sacred scriptures' places by identifying the biblical toponyms. It was also an "Ecclesiastical Geography" that mapped the spatial distribution of religions to support the cartography's symbolic and religious dimension (Giorda, 2019a, pp. 202-204). This was the trend up to the 18 th century, often based on a religious and confessional debate on maps.

More recently, the patial turn n Religious Studies has determined a new reconsideration of the concept of space/place within the interdisciplinary field of studies regarding religions. According to Kim Knott (2014), the focus on space allows exploring the venues where religion is situated, the relationships between religion and the secular, the localization of religious people, and the processes of creation of religious communities. Both media and the Internet, in particular, change the perception of religious and secular spaces by allowing faster communications and creating global networks (Kong, 2001). This affects both the dimension of politics and poetics of space and their aesthetics, as well as the symbolic dimension, cultural perception, materiality, infrastructure, related management, conflicts, and mediation. This "dynamism of space", as Knott called it (Knott, 2010, pp. 36-37; Giorda, 2019b, p. 12), is related to social knowledge and power, history and time, condition of simultaneity, and the different ways in which space is experienced, represented, and lived.

Both Religious Studies scholars' interest in space, and the geographers' interest in religion (exemplified by Dwyer's (2016) eloquent title, "Why does religion matter for cultural geographers?"), have triggered a process of autonomization of the "Geography of Religions". Thus, religions have become an interesting topic also for geographers and, after the spatial turn in Religious Studies, new research has been conducted around topics like space and place, often in an interdisciplinary perspective. This also creates possibilities to study migrations, pilgrimages, ecology, infrastructures, cities and architectures, and finally, the coexistence of religions in the same spaces (Giorda, 2019a, 214-216, Burchardt and Giorda forthcoming).

In his article about the spatial turn, Lionel Obadia emphasized that the concepts of "spatial turn" and "geographic turn" are concomitant and logically associated with that of "mobility turn" (Obadia, 2015, p. 2002), which was portrayed by Kevin Hannam, Mimi Sheller, and John Urry as a "paradigmatic alternative to a 'sedentarist' approach in the social sciences, that treats place, stability and dwelling as a natural steady state" (Hannan, Sheller \& Urry, 2006, p. 6, quoted by Obadia, 2015, p. 2002). We think that this concept of mobility, related to that of multiple identities, can be very useful in a continuously evolving and changing idea of space (Burchardt \& Griera, 2020). Thus, space has a dynamic identity which is related to anthropological attitudes and habits. 
As already pointed out elsewhere (Giorda, 2020), space is a larger environment, socially constructed and reproduced as a result of the interplay of different actors, through different practices, beliefs, and representations. Within this broader and more abstract notion, place is a significant and material portion of space (Harvey, 1991; Creswell, 2004; Knott, 2010c; Giorda, 2019a). For this reason, we prefer to refer to places in a plural way. Drawing on these approaches, the concept of "place" includes, also, the religious place. This is a particular category of place that is made meaningful by a group of people who inhabit it and construct its ritual and cultural characteristics: they frame it, establish rules, practice religious rituals, and create cultural and religious forms of afffiliation (Giorda, 2020). From a practical perspective, everyday religion has the potential to create places in different locations and, at the same time, different religions can coexist in the same place. For this reason, we can think about space on different levels and refer to space as a context but also as an actor. The articles in this special issue employ the terminology of both "place" and "space," to indicate physical venues where religious practices occur, online environments that host religious narratives, and the process of space-creation that involves religious meanings and values.

Particulary interesting is the concept of shared spaces (Burchardt \& Giorda, 2021), which stresses the importance of mixing identities and meeting different cultures and religions within the same space. Different kinds of dynamics are present in multi-religious spaces, something that can also be connected to religion on the Internet. Because of the proliferation of narratives about Islam in Internet spaces, it is possible to observe discourses from Muslim and not-Muslim actors, as well as strategies of narrations, speaking, and representing. In the next section, we will discuss the notion of space in relation to online practices.

\section{Digital Religion and the Notion of Space}

The study of religion and media has been increasingly interested in the growth of online - or "virtual" - religious spaces. Throughout the 199os and the early 20oos, scholars have often talked about "cyber religion" as a type of religion that existed primarily in online settings, or "cyberspaces" (Brasher, 2004). This leads to the distinction of "religion online" and "online religion," where the former indicates the online transposition of religious practices and the use of the Internet by religious groups based in physical spaces, while the latter includes all the religious practices and narratives that exist exclusively online (Helland, 
200o). However, the growth of Internet-based practices and the proliferation of religious web pages and platforms made this distinction increasingly blurred (Pace, 2013). There are, therefore, two overlapping processes: the first one is represented by a continuous exchange between religions online and offline, with a progressive occupation of the web by religions who establish practices and narratives in this space; the second one is the entanglement of secular and religious narratives in online settings.

In thinking about online and offline positions as integrated rather than mutually excluded, we are inspired by the concept of "onlife" interconnections, as explained by Luciano Floridi (2015). This perspective insists on considering the blurring distinctions between reality and virtuality, and the progressive entanglements between humans, machines, and nature. Following this line of reasoning, we aim to explore how religion and the Internet form new types of experiences and practices. Therefore, the definition that is more appropriate for the case studies in this special issue, and that is widely employed in the field of religion and media, is that of "digital religion" (Campbell, 2012). ${ }^{2}$ The term digital religion indicates an "onlife" interconnection of the online and the offline dimension and "the technological and cultural space that is evoked when we talk about how online and offline religious spheres have become blended and integrated" (Campbell \& Evolvi, 2019, p. 2).

In looking at digital and physical spaces that participate in the creation of religious imaginaries and practices, we focus on the "in-between" (Bhabha, 1996) and hybrid (Giorda \& Longhi, 2019; Erne, 2017) characteristics of Internet spaces. Hence, the intersection between online and offline practices, as in the aforementioned definition, may be generative of spaces for cultural performances and meaning creations. Digital religion, therefore, also entails the possibility of new spaces that exist between the Internet and the physical dimension. For this reason, some scholars have critically applied the concept of "third space" or "third place" to Internet practices (Hoover \& Echchaibi, 2014; Pennington, 2018). A term borrowed from architecture and sociology (Soja, 1996), third space in this context indicates the fluidity of practices in a space that exists exclusively because of the possibilities of the Internet, but at the same time is connected to and has an impact on everyday religious practices and experiences. Drawing from the notion of hybrid culture elaborated by Homi Bhabha (1996), the digital third space approach conceptualizes the possibility of creatively negotiating religious narratives, identities, and practices by employing new technologies. While Bhabha considered third spaces as existing at the intersection of the colonizer and the colonized culture, the

2 See also the project https://digitalreligion.tamu.edu. 
digital third space allows for religious imaginaries that foster interconnections between individuals and groups, and also points to the heterogeneity of religious and cultural practices. Hence, religious groups and individuals use the Internet to create hybrid spaces that have some of the characteristics of physical venues and are also influenced by online culture. These spaces are increasingly important in the negotiation of religious meanings.

The notion of third space is critically evaluated in some of the articles of this volume. In Susanne Stadlbauer's article, the British YouTube channel Salfimedia UK is analyzed as an example of third space. By drawing from Bhabha's conceptualization of third space and cultural hybridity, Stadlbauer analyzes how some Salafi expressions online merge old and new forms of sociality and communication. The affordances and the pervasiveness of digital media allow certain Salafi channels to recreate spaces of practice and be symbolically connected to a perceived Salafi "self" attached to traditionalist Islamic dogmas. With the term "hybridic purity," Stadlbauer describes the Internet as a space for the creation of discourses that negotiate the role of Islam in the West.

However, the notion of third space is critically problematized by the article of Carmen Becker. Looking at Salafi spaces, based in German and the Netherlands, Becker reflects on the notion of "religion/the religious" embedded in the definitions of digital religion and third space. As Becker notices, the category of religion should not be naturally given, but analyzed within discursive frameworks and material contexts. The Salafi digital spaces analyzed by Becker employ aural and visual markers that point to what is perceived as appropriate and authentic, in a continuous negotiation of religious feelings. For this reason, rather than describing them as third spaces, Becker proposes to think of digital venues as generative spaces that are simultaneously structured and structuring.

The article by Lale Mahmudova and Giulia Evolvi also employs the notion of hybrid third spaces. In this case, the theory is applied to the digital media practices of young Muslim women in the Netherlands, who find strategies to create Instagram narratives that conciliate the values of their community of origin and Dutch society's expectations. In this case, the framework of third space is critically connected with the notion of composite habitus. By employing this framework, Mahmudova and Evolvi analyze digital spaces as mirroring practices of young Muslim women, whose behaviors and cultural imaginaries are produced by the specific dispositions of their social situations.

\section{Materiality and the Internet}

The potential of the Internet in creating third spaces is also connected to material practices. While digital practices might give the idea of being detached 
from physical experiences, they are often rooted in materiality. The attention to materiality in the field of digital religion is connected to the growing focus on materiality in the field of Religious Studies. Hence, material practices are increasingly considered a fundamental mode of knowledge that completes abstract and transcendental elements (Houtman \& Meyer, 2012). When it comes to religion in online spaces, materiality is not erased, but it is negotiated thanks to digital technology. It is for this reason that the Internet can be conceptualized as a concrete example of space where a "lived religion" is performed in daily practices (McGuire 2008): this approach of "doing religion" (Burchardt \& Griera, 2020) is fruitful to explore both the individual and collective, the material and immaterial, the visible and invisible, the normative and real (and also the exceptional) dimension of online spaces. As Hutchings (2016) writes, the Internet embeds materiality in various ways. For instance, online spaces may have concrete effects on how people materially display and perceive religion within physical spaces. Various articles in this special issue discuss aspects of material religion in relation to the Internet.

The article of Luca Patrizi focuses on visual representations of Islam, analyzing movies that depict the life of the Prophet and other Muslim themes. In this case, the diffusion of movies through online platforms contributes to giving a visual and aesthetic perspective on Muslim practices and traditions (i.e. the Ramadan), and to representing the places historically connected to Islam in cinematic revisitation. Patrizi's article not only discusses films as spaces of transnational religious representation and negotiation, but also reflects on the material and immaterial stratagems of the filmmakers to conform to the Muslim faith, sometimes matching religious, cultural, and political needs, for instance by not directly depicting the Prophet Muhammad.

Alessandra Vitullo's article explores the proliferation of online Islamophobia in its material consequences. By critically presenting data collected in various European contexts and focusing on the case study of anti-Muslim hate speech in Italy, Vitullo shows that the Internet is not only a space of self-representation, but can also constitute a fertile terrain for discrimination and racism. Moreover, online Islamophobia is embedded and connected with offline abuses, showing how the Internet can also result in street-level harassment in physical spaces.

The article of Kristin Peterson analyzes the photographic project "Places You'll Pray" by photographer Sana Ullah, who captured Muslims praying in various public spaces in America. The project exemplifies how people can reproduce material and embodied religious practices online. Ullah's pictures show how Muslims search for aesthetic qualities in the physical spaces they use to pray, but also how the visible presence of Muslim bodies can be normalized within U.S. society by circulating pictures on the Internet. According 
to Peterson, digital venues have the potential to help Muslims articulate their voices through images and create aesthetic spaces for political involvement.

Farah Hasan describes how Muslim men articulate their identities on the Muslim dating app Muzmatch. Based on a digital ethnography, the study employs the notion of Islam as a discursive tradition to explore the practices of identity articulation that happen through the app. By analyzing how male app users negotiate traditions, agency, and personal relations, Hasan discusses how digital technologies can reshape materiality and location. In particular, users employ the app to talk about material aspects of their everyday dating life and to find suitable partners within and beyond the local places where they live.

\section{Conclusion}

The articles in this special issue highlight the interconnections of online and offline spaces. From this perspective, third spaces are not solely conceptual, but they create hybrid religious performances that reproduce existing locations and material practices and impact everyday religious experiences. There are some concluding remarks that we wish to offer.

First, the Internet connects people and has accelerated the opportunities for fast networks of communication. However, despite the logic of globalization, social media create communities which are often anchored to a local geographical context, since people share languages, interests, and needs. The articles in this special issue show how case studies about digital religion often continue to use the local dimension as a framework for reference. It is therefore theoretically important to highlight the progressive expansion of local groups and communities discussing local references on digital platforms. In this sense, the continuous exchange between the international dimension and the local one sheds light on how the Internet doesn't transcend space, but rather re-defines it, reinforcing networks, building communities, and relating to offline experiences.

Second, in this special issue, we have collected articles that focus on various platforms, such as YouTube, forums, Instagram, film streaming, and dating apps. It is important to consider the affordances of each platform and its potential in amplifying or hindering Muslim voices. Because of the rapid circulation and interconnections of Internet spaces, narratives are often not limited to a single venue, but are spread across platforms. Therefore, there is a need to think about theoretical approaches -such as that of digital religion -that not only stress the connections between online and offline spaces, but also consider the interconnections between digital media and the so-called traditional media, as well as between different media platforms. 
The interdisciplinary approaches explored in this special issue open questions and offer some possibilities for future research. First of all, a venue for future research would be the role and the use of social networks in the resilience and the development of religions: how do Twitter, Instagram, Tik Tok, and other emerging digital platforms affect everyday religious practices? We suggest that, together with the proliferation of social networks, it would be interesting to conduct analyses of religions on web-tv and series, in particular their circulation, stereotypes, and simplifications. This will allow for the study of the cultural and economic backgrounds of the success of television streaming and TV series about religion as media products, and their connections with digital platforms.

Secondly, we hope that the debate on religion, space, and the Internet can be extended to religions other than Islam, with a focus on their presence, their agencies, and their positions in the public debate, as actors or objects of discussion, both in a local and in a global dimension. Connected to this point, scholars should analyze the long-term results and products of Covid-19 on religion: research is being conducted on the effects of the pandemic crisis on the material organization of religions and it would be interesting to reflect on how these changes will perdure in the future. We would argue that the concept of hybridity and "in-betweenness", as well as blended modalities of expression, will continue to be relevant. Lastly, from a methodological perspective, this special issue collected qualitative articles, mostly based on interviews and textual or visual analysis. However, there is also a need to explore how religions can be objects of new tools of digital research: for instance, a venue for future research would be to inquire the benefits, limits, practices and policies in using big data approaches and Digital Humanities (Cantwell \& Petersen, 2021). We think that this field is not only fruitful for processing quantitative data, but also for its contribution in inspiring new epistemologies.

In conclusion, we hope that this special issue can open up a venue for conversations on the use of a spatial approach in the study of digital religion, and that it will help scholars conceptualize different religious practices across physical spaces and digital platforms.

\section{References}

Awan, I. (2014). Islamophobia and Twitter: A Typology of Online Hate Against Muslims on Social Media. Policy \& Internet, 6 (2), pp. 133-15o.

Bahfen, N. (2018). The Individual and the Ummah: The Use of Social Media by Muslim Minority Communities in Australia and the United States. Journal of Muslim Minority Affairs, 38 (1), 119-131. 
Bhabha, H. K. (1996). Culture's In-Between. In: Stuart Hall, Paul du Gay, eds., Questions of Cultural Identity. Thousand Oaks: Sage, pp. 53-6o.

Brasher, B. E. (2004). Give Me That Online Religion. New Edition. New Brunswick: Rutgers University Press.

Borrillo, S. (2017). Femminismie Islam in Marocco. Attiviste laiche, teologiche, predicatrici. Edizioni Scientifiche Italiane.

Burchardt, M. \& Giorda, M. (forthcoming 2021). Geographies of Encounter: The Making and Unmaking of Multireligious Spaces. London: Palgrave.

Burchardt, M. \& Griera, M. (2020). Doing Religious Space in the Mediterranean City: Towards a Historical Sociology of Urban Religion. In: S. Rau \& J. Rüpke, eds., Religion and Urbanity Online. Berlin: De Gruyter. Retrieved from: <https://www.degruyter. com/document/database/URBREL/entry/urbrel.13215539/html>.

Burchardt, M., \& Höhne, S. (2015). The Infrastructures of Diversity: Materiality and Culture in Urban Space - An Introduction. New Diversities 17(2), pp. 1-13. Retrieved from <https://newdiversities.mmg.mpg.de/?page_id=2139>.

Campbell, H. A., ed. (2012). Digital Religion: Understanding Religious Practice in New Media Worlds. Abingdon: Routledge.

Campbell, H. A., \& Evolvi, G. (2019). Contextualizing current digital religion research on emerging technologies. Human Behavior and Emerging Technologies 2 (1), pp. $5^{-17}$.

Cantwell, C. D. \& Petersen, K., eds. (2021). Digital Humanities and Research Methods in Religious Studies: An Introduction. Berlin: De Gruyter.

Cresswell, T. (2004). Place: A Short Introduction (1st edition). Hoboken:Wiley-Blackwell.

Dwyer, C. (2016). Why does religion matter for cultural geographers? Social \& Cultural Geography $17(6)$, pp. $75^{8-762 .}$

Echchaibi, N. (2011). Voicing Diasporas: Ethnic Radio in Paris and Berlin Between Cultural Renewal and Retention. Washington, DC: Lexington Books.

Echchaibi, N. (2013). Muslimah Media Watch: Media activism and Muslim choreographies of social change. Journalism 14 (7), pp. 852-867.

Elfenbein, C., Bakaari, F. \& Schafer, J. (2021). Mapping Anti-Muslim Hostility and Its Effects. In: Cantwell, C. D. \& Petersen, K., eds., Digital Humanities and Research Methods in Religious Studies: An Introduction. Berlin: De Gruyter, 249-272.

Erne, T. (2017). Hybride Räume der Transzendenz: Wozu wir heute noch Kirchen brauchen. Studien zu einer postsäkularen Theorie des Kirchenbaus (1st edition). Leipzig: Evangelische Verlagsanstalt.

Evolvi, G. (2017a). \#Islamexit: Inter-group antagonism on Twitter. Information, Communication \& Society 22 (3), pp. 386-401.

Evolvi, G. (2017b). Hybrid Muslim identities in digital space: The Italian blog Yalla. Social Compass $64(2)$, pp. 220-232. 
Floridi, L., ed. (2015). The Onlife Manifesto: Being Human in a Hyperconnected Era. Berlin: Springer International Publishing.

Frisina, A. (2011). The Making of Religious Pluralism in Italy: Discussing Religious Education from a New Generational Perspective. Social Compass 58 (2), pp. 271-284. Giorda, M. (2019a). Geografia delle religioni. In: G. Filoramo, M. Giorda N. Spineto, eds., Manuale di Scienze della religione, Morcelliana Scholé: Brescia, pp. 201-222.

Giorda M. (2019b). Geography of Religions: Introduction. Historia Religionum 11, pp. 11-14.

Giorda, M. (2020). Territori, Spazi e Luoghi Religiosi / Territories, Spaces and Religious Places. Metamorfosi, Quaderni di Architettura 8, pp. 20-27.

Giorda, M., \& Longhi, A. (2019). Religioni e spazi ibridi nella città contemporanea: profili di metodo e di storiografia. Atti e Rassegna Tecnica della Società degli Ingegneri e degli Architetti in Torino 152, 73 (2), pp. 108-116.

Hannam K., Sheller, M. and Urry, J. (2006). Editorial: Mobilities, Immobilities and Moorings. Mobilities 1 (1), pp. 1-22.

Harvey, D. (1991). The Condition of Postmodernity: An Enquiry into the Origins of Cultural Change. Hoboken: Wiley-Blackwell.

Helland, C. (2000). Online Religion/Religion Online and Virtual Communitas. In: J. K. Hadden \& D. E. Cowan, eds., Religion on the Internet. Bingley: Emerald, pp. $205^{-224 .}$

Hoover, S., \& Echchaibi, N. (2014). The Third Spaces of Digital Religion. Retrieved from <https://www.researchgate.net/publication/287644204_The_Third_ Spaces_of_Digital_Religion>.

Houtman, D., \& Meyer, B. (2012). Things: Religion and the Question of Materiality. New York: Fordham University Press.

Hutchings, T. (2016). Augmented Graves and Virtual Bibles. In T. Hutchings \& J. McKenzie, eds., Materiality and the Study of Religion: The Stuff of the Sacred. Abingdon: Routledge, pp. 85-99.

Hutchings, T., \& McKenzie, J. eds. (2016). Materiality and the Study of Religion: The Stuff of the Sacred. Abingdon: Routledge.

Knott, K. (2010). Cutting Through The Postsecular City: A Spatial Interrogation. In: A. Molendijk, J. Beaumont \& C. Jedan, eds., Exploring the Postsecular: The Religious, the Political and the Urban. Leiden: Brill, pp. 19-38.

Knott, K. (2014). The Location of Religion: A Spatial Analysis. Abingdon: Routledge.

Kong, L. (2001). Mapping 'New' Geographies of Religion: Politics and Poetics in Modernity. Progress in Human Geography 25 (2), pp. 211-233.

McGuire, M. B. (2008). Lived Religion: Faith and Practice in Everyday Life. Oxford: Oxford University Press.

Obadia, L. (2015) Spatial Turn, Beyond Geography: A New Agenda for Sciences of Religion? International Review of Sociology 25 (2), pp. 200-217. 
Pace, E. (2013). La comunicazione invisibile: Le religioni in internet. Cinisello Balsamo: San Paolo Edizioni.

Pennington, R. (2018). Social Media as Third Spaces? Exploring Muslim Identity and Connection in Tumblr. International Communication Gazette 8o (7), pp. 620-636.

Peterson, K. M. (2016). Beyond Fashion Tips and Hijab Tutorials: The Aesthetic Style of Islamic Lifestyle Videos. Film Criticism 40 (2), article 3. Retrieved: <https://quod.lib. umich.edu/f/fc/13761232.0040.203>.

Peterson, K. M. (2020). The Unruly, Loud, and Intersectional Muslim Woman: Interrupting the Aesthetic Styles of Islamic Fashion Images on Instagram. International Journal of Communication 14, 1194-1213. Retrieved from <https://ijoc. org/index.php/ijoc/article/view/12715>.

Soja, E. W. (1996). Thirdspace: Journeys to Los Angeles and Other Real-and-Imagined Places. Blackwell Publishers.

Vitullo, A. (2019). Radicalizzarsi online. Islamofobia e discorsi d'odio in rete. In S. Hejazi, B. Maria, \& G. M. Chiara, eds., Capire l'Islam: Mito o realtà? Brescia: Morcelliana.

Wheeler, K. R. (2014). Remixing Images of Islam: The Creation of New Muslim Women Subjectivities on YouTube. Online - Heidelberg Journal of Religions on the Internet 6 , pp. 144-163. Retrieved from <https://heiup.uni-heidelberg.de/journals/index.php/ religions/article/view/17364>.

Zoonen, L. van, Vis, F., \& Mihelj, S. (2011). YouTube Interactions Between Agonism, Antagonism and Dialogue: Video Responses to the Anti-Islam Film Fitna. New Media \& Society 13 (8), pp. 1283-1300. 